Int. J. Curr. Res. Med. Sci. (2016). 2(11): 35-41

International Journal of Current Research in Medical Sciences

ISSN: 2454-5716

www.ijcrims.com

Volume 2, Issue 11 -2016

\title{
Pattern of adult lymphadenopathy among patients attending King Khalid hospital, Majmaah province, Kingdom of Saudi Arabia
}

\author{
Salah A Abdelrahim ${ }^{1 *}$, Ashraf A Deyab ${ }^{1}$, Elsadig Y Mohamed ${ }^{2}$, Abdul Lateef $\mathbf{J}^{3}$ \\ ${ }^{1}$ Faculty of Medicine, Department of Pathology, Majmaah University, \\ Al Majmaah, Kingdom of Saudi Arabia \\ ${ }^{2}$ Faculty of Medicine, Department of Community Medicine and Public Health, Majmaah University, \\ Al Majmaah, Kingdom of Saudi Arabia \\ ${ }^{3}$ Faculty of Medicine, Department of Biochemistry, Majmaah University, \\ Al Majmaah, Kingdom of Saudi Arabia \\ For correspondence: Salah Ahmed Abdelrahim \\ E-mail: shaaa88@hotmail.com, s.abdelrahim@mu.edu.sa
}

Tel: 00966532416304

\section{Abstract}

Background: Although lymphadenopathy is a common presentation in clinical practice and no previous work was done in this region to assess it, this study was aimed to determine its causes and distribution among adult patients and highlight the gender, age, nationality of patients, number of enlarged lymph nodes and the commonest site of biopsies.

Methods: Retrospectively data from lymph node biopsy specimens received at histopathology laboratory, King Khalid Hospital, Majmaah province, Saudi Arabia from January 2009 to December 2013 was reviewed and analyzed using SPSS version 21 software.

Results: Of 54 cases of lymph node biopsies received, 28 (51.9\%) were males and 26 (48.1\%) were females giving male: female ratio 1.1: 1. The age of the patients ranged from 15 to 90 years. The commonest site of biopsies was cervical $(61.1 \%)$ followed by mesenteric $(20.4 \%)$ and axillary $(11 \%)$. The benign pattern was observed in $(72.2 \%)$ of cases while the malignant was observed in $(27.8 \%)$ of cases. Malignant pattern was noticed more in elderly peoples with male predominance (60\%). Reactive lymphoid hyperplasia (31.5\%), tuberculous lymphadenitis (27.8\%), Hodgkin`s lymphoma (13\%) were the commonest causes of lymphadenopathy.

Conclusions: Among the received cases of lymphadenopathy reactive lymphoid hyperplasia was found to be the most common cause followed by tuberculous lymphadenitis and hodgkin's lymphoma.

Keywords: Lymphadenopathy, Pattern, Majmaah province, Saudi Arabia 


\section{Introduction}

Lymphadenopathy refers to nodes that are abnormal in size, consistency or number. It is a commonly encountered clinical problem in all branches of medicine. Studies have shown that as many as $56 \%$ of patients examined for other reasons were found to have cervical lymphadenopathy Abdullah A. abba(2002). Lymphadenopathy can be caused by a number of diseases manifest in various forms in different ages and regions worldwide (Habermann TM et al., 2000). Reactive lymphoid hyperplasia has been reported as a significant cause of lymphadenopathy in children (Kelly CS et al., 1998) while malignancy has been reported as major cause in adult (Lee JG et al., 1970). Tuberculosis remains a major problem in developing countries and among immigrant populations in developed world Abdullah A Abba (2006), while malignancy is documented as the major cause of lymphadenopathy in developed world (Talvalkar GV et al., 1973; Siddiqui N et al., 2006). In the literature there are a number of publications from all over the world on lymphadenopathy but in this region there is paucity of information on the spectrum of diseases affecting lymph nodes and the distribution of them among the population. However this study was conducted with the aim to determine the causes and distribution of lymphadenopathy and compare the results with the regional and international studies.

\section{Materials and Methods}

All adult cases (15 years and above) of lymph node biopsies received at histopathology laboratory of King Khalid hospital, Majmaah, Kingdom of Saudi Arabia from January 2009 until December 2013 were retrospectively reviewed. The patients data regarding sex, age, biopsy site and histopathological diagnosis were obtained from request forms and case records using a check list. Data collected and analyzed using SPSS version 21 software.

\section{Results}

Fifty four lymph node biopsies of adult patients were received at histopathology laboratory of
King Khalid Hospital, Majmaah, Saudi Arabia from January 2009 to December 2013. There were 28 (51.9\%) males and $26(48.1 \%)$ females giving male: female ratio of 1.1: 1 . Half of the patients were younger age group (15-30 years) while the other half was older age group (31 years and more) with 15 years was the youngest age and 90 years was the oldest age of patients. Thirty six (66.7\%) of cases were from Saudi, the majority of them were males constituting $20(55.6 \%)$ and 18 $(33.3 \%)$ were from other nationalities, the majority of them were females constituting 10 $(55.6 \%)$. Twenty one $(38.9 \%)$ of cases were from Majmaah province and the remaining $33(61.1 \%)$ cases were from other areas outside Majmaah province (Table 1). Forty three (79.6\%) of studied cases were found to have a single group of enlarged lymph nodes while $11(20.4 \%)$ cases were found to have more than one group of enlarged lymph nodes. Sites from where the received biopsies were excised was different with the cervical being the most common site constituting $33(61.1 \%)$ cases followed by mesenteric (20.4\%) and axillary (11\%) (Table 2). Regarding the histopathology of biopsies the benign pattern was observed in $39(72.2 \%)$ cases, of which $22(56.4 \%)$ were inflammatory with tuberculous lymphadenitis predominance constituting $15(68.2 \%)$ of cases. The malignant pattern was observed in $15(27.8 \%)$ cases, of which $11(73.3 \%)$ cases were primary in origin with Hodgkin`s lymphoma predominance representing 7 (46.7\%) of cases while 4 (26.7\%) cases were secondary spread from other organs. Benign cases were found more frequently among females constituting $20(51.3 \%)$ while malignant cases were found more frequently among males constituting $9(60 \%)$ of cases. The benign cases were found more frequent in the age group (15 30) years representing $53.8 \%$ of cases while the malignant cases were much more frequent in the age group (31 year and more) representing 60\% of cases. The malignant pattern was observed more frequent among Saudi patients constituting $80 \%$ of cases (Table 3 and 4 ). Of the fifty four cases $17(31.5 \%)$ were diagnosed as reactive lymphoid hyperplasia. Tuberculous lymphadenitis was observed in 15 (27.8\%) cases. Seven (13.0\%) of studied biopsies diagnosed as Hodgkin`s lymphoma with nodular sclerosis pattern was the 
Int. J. Curr. Res. Med. Sci. (2016). 2(11): 35-41

Most common. Chronic non-specific lymphadenitis was observed in $5(9.3 \%)$ cases. Non-Hodgkin`s lymphoma constituted 4 (7.4\%) of cases. Metastasis in studied biopsies was seen in $4(7.4 \%)$ of cases mainly in received mesenteric lymph node biopsies. Only two (3.6\%) of the studied biopsies were diagnosed as necrotizing (Kukuchi) lymphadenitis (Table 5).

Table (1). Demographic data of the sample

\begin{tabular}{|c|c|c|}
\hline Social factor & Frequency & Percent \\
\hline \multicolumn{3}{|l|}{ Gender: } \\
\hline - Male & 28 & 51.9 \\
\hline Female & 26 & 48.1 \\
\hline Total & 54 & 100 \\
\hline \multicolumn{3}{|l|}{ Age: } \\
\hline $15-30$ & 27 & 50 \\
\hline 31 and more & 27 & 50 \\
\hline Total & 54 & 100 \\
\hline \multicolumn{3}{|l|}{ Nationality: } \\
\hline - Saudi & 36 & 66.7 \\
\hline Non-Saudi & 18 & 33.3 \\
\hline Total & 54 & 100 \\
\hline \multicolumn{3}{|l|}{ Residence: } \\
\hline - Majmaah & 21 & 38.9 \\
\hline Outside Majmaah & 33 & 61.1 \\
\hline Total & 54 & 100 \\
\hline
\end{tabular}

Table (2). Number of Enlarged Lymph Node group and Site of Biopsy

\begin{tabular}{|c|c|c|}
\hline Number and site & Frequency & Percent \\
\hline $\begin{array}{l}\text { Number: } \\
\text { - Single group } \\
\text { - More than one group } \\
\text { Total }\end{array}$ & $\begin{array}{l}43 \\
11 \\
54\end{array}$ & $\begin{array}{c}79.6 \\
20.4 \\
100\end{array}$ \\
\hline $\begin{array}{ll}\text { Site: } & \\
- & \text { Cervical } \\
- & \text { Mesenteric } \\
- & \text { Axillary } \\
- & \text { Head } \\
- & \text { Inguinal } \\
\text { Total } & \end{array}$ & $\begin{array}{c}33 \\
11 \\
6 \\
3 \\
1 \\
54\end{array}$ & $\begin{array}{c}61.1 \\
20.4 \\
11 \\
5.6 \\
1.9 \\
100\end{array}$ \\
\hline
\end{tabular}


Int. J. Curr. Res. Med. Sci. (2016). 2(11): 35-41

Table (3). Histopathology characteristics of Biopsies

\begin{tabular}{|l|c|c|}
\hline \multicolumn{1}{|c|}{ Characteristic } & Frequency & Percent \\
\hline Pattern: & 39 & \\
$-\quad$ Benign & 15 & 72.2 \\
$-\quad$ Malignant & 54 & 27.8 \\
Total & 22 & 100 \\
Benign: & 17 & 56.4 \\
$-\quad$ Inflammatory & 39 & 43.6 \\
$-\quad$ Non-inflammatory & 11 & 100 \\
$\quad$ Total & 4 & 73.3 \\
Malignant: & 15 & 26.7 \\
$-\quad$ Primary & & 100 \\
Secondary & & \\
\hline Total & & \\
\hline
\end{tabular}

Table (4). Histopathology of biopsies and demographic data

\begin{tabular}{|l|c|c|c|c|}
\hline \multirow{2}{*}{ Social factors } & \multicolumn{2}{|c|}{ Benign } & \multicolumn{2}{c|}{ Malignant } \\
\cline { 2 - 5 } Gender: & No. & Percent & No. & Percent \\
Male & 19 & 48.7 & 9 & 60 \\
Female & 20 & 51.3 & 6 & 40 \\
Total & 54 & 100.0 & 15 & 100 \\
Age (years): & & & & \\
15-30 & 21 & 53.8 & 6 & 40 \\
31and more & 18 & 46.2 & 9 & 60 \\
$\quad$ Total & 39 & 100.0 & 15 & 100 \\
Nationality: & & & & \\
Saudi & 24 & 61.5 & 12 & 80 \\
Non-Saudi & 15 & 38.5 & 3 & 20 \\
Total & 39 & 100.0 & 15 & 100 \\
& & & & \\
\hline
\end{tabular}

Table (5) Histopathology Diagnosis

\begin{tabular}{|l|c|c|}
\hline \multicolumn{1}{|c|}{ Diagnosis } & Frequency & Percent \\
\hline Reactive lymphoid hyperplasia & 17 & 31.5 \\
Tuberculous lymphadenitis & 15 & 27.8 \\
Hodgkin`s lymphoma & 7 & 13.0 \\
Chronic non-specific lymphadenitis & 5 & 9.3 \\
Non-Hodgkin`s lymphoma & 4 & 7.4 \\
Metastasis & 4 & 7.4 \\
Kukuchi (necrotizing lymphadenitis) & 2 & 3.6 \\
Total & 54 & 100 \\
\hline
\end{tabular}




\section{Discussion}

Fifty four lymph node biopsies were reviewed in this retrospective study at the histopathology laboratory of King Khalid hospital, Majmaah province, Saudi Arabia from January 2009 to December 2013. Our study revealed slight male predominance $(51.9 \%)$ giving male: female ratio 1.1: 1 . This finding is in agreement with the study in Saudi Arabia of (Albasri A.M et al, 2014) and others from other countries Ageep A.K (2012) and (Olu-Eddo et al., 2006). Our finding was different from that in Saudi Arabia reported by Abdullah A. abba (2002) in which females were predominant. The age of studied cases ranged from 15 to 90 years with equal distribution of biopsies among age groups. In this study most of the biopsies were of Saudi patients. This is similar to other reports from other regions of Saudi Arabia (Abdullah A. abba, 2002; Albasri A.M et al., 2014). In the majority of the received cases lymphadenopathy was localized involving a single group of lymph nodes representing (79.6\%), in Saudi Arabia the same finding was reported in study of Abdullah A. abba (2002). The cervical lymph nodes were the commonest site of biopsy accounting (61.1\%). This observation is consistent with most recent studies in different regions in Saudi Arabia (Albasri A.M et al., 2014) and other countries (Ageep A.K, 2012; Olu-Edd et al., 2006), this may be due to easy accessibility of cervical lymph nodes for biopsy and that they drain the most commonly affected region of the body. In this study the benign lesions were predominantly observed while malignant lesions were less common. This is finding is in agreement with the study of (Al-Twfiq and Raslan, 2012) but in disagreement with other studies in Saudi Arabia and outside Saudi Arabia (ALbasri A.M et al., 2014; Roy et al.,2013) in which malignant lesions were predominant. The benign lesions were more commonly observed among females while the malignant lesions were commonly observed among males in agreement with the study of (Albasri A.M et al., 2014). Regarding the causes of lymphadenopathy our study revealed that the commonest causes were reactive lymphoid hyperplasia followed by tuberculous lymphadenitis and neoplastic diseases. This finding contradicts studies from Saudi Arabia and other countries. In Saudi Arabia one of the studies reported that the commonest causes of lymphadenopathy were neoplastic lesions followed by reactive lymphoid hyperplasia and tuberculous lymphadenitis respectively (Albasri A.M et al., 2014), other one documented that the commonest causes were tuberculous lymphadenitis followed by neoplastic diseases Abdullah A. abba (2002). On the other hand the study from Sudan reported that the commonest causes were tuberculosis followed by metastatic diseases Ageep A.K (2012), while other from Pakistan reported tuberculosis was the commonest cause followed by neoplastic (Nasseem et al., 2011) and study from India showed that the commonest causes were neoplastic lesions followed by reactive lymphoid hyperplasia and tuberculous lymphadenitis (Roy et al., 2013). Reactive lymphoid hyperplasia was found to be the commonest cause of lymphadenopathy despite exclusion of children in this study in whom reactive hyperplasia is more common (Kelly CS et al., 1998). The study like others from developing countries showed a high prevalence of tuberculous lymphadenitis with higher proportion among Non-Saudi, this can be explained partly by low socioeconomic status of these patients and the other thing that they are from countries where the prevalence of the disease is high in agreement with (Powell DA et al., 1999; Abdullah A. abba, 2002; Al-Tawfiq-Raslan, 2012). Malignant lymphoma (Hodgkin`s, Non-Hodgkin`s) came in the third place of commonest causes of lymphadenopathy this finding is in disagreement with the studies of Abdullah A. abba (2002) where it mentioned as the second commonest cause and of (Albasri A.M et al., 2014), in which lymphoma is the most frequent lymph node pathology diagnosis. Similar to other studies in other regions of Saudi Arabia Abdullah A. abba (2002) and (Albasri A.M et al., 2014) this study revealed Hodgkin`s lymphoma predominance with nodular sclerosis pattern was the commonest histological type followed by mixed cellularity type but this finding is contradicts that reported by (Alsohaibani M.O et al., 1990; Morad N et al., 1990) where Non-Hodgkin`s lymphoma is more common and mixed cellularity was the most common Hodgkin`s lymphoma type. This variation between previous and recent results may 
be represent recent shift towards the pattern in developed countries (O Conor GT et al., 1973; Stalsberg $\mathrm{H}$ et al., 1973). Our finding also showed metastatic disease more common in older age groups similar to the finding of Abdullah A. abba (2002). Kikuchi's disease also was observed in this study with predominance in younger age group and equal distribution among male and female and more commonly observed in mesenteric lymph nodes biopsies in disagreement with the study of Abdullah A. abba (2002) in which the disease is more common in female and found in cervical lymph node biopsies more.

In conclusion our study revealed that Lymphadenopathy was common among males gender and Saudi Nationals. The majority of biopsies were obtained from patients had a single group of enlarged lymph nodes with the commonest site of biopsies was cervical group followed by the mesenteric and axillary consecutively. Benign pattern was more common than malignant with inflammatory lesions predominance while in malignant pattern primary lesions were the commonest. Reactive lymphoid hyperplasia was the commonest cause of lymphadenopathy followed by tuberculosis and malignancy. There were similarities and differences between these findings and others in previous studies from Saudi Arabia and elsewhere. Finally these findings may form a baseline for further research studies in this region.

\section{References}

Abdullah A Abba. Clinical experience with Tuberculous Lymphadenitis in Central Saudi Arabia. In JK-Practitioner 2006; 13(2):83-86

Abdullah A. abba. Lymphadenopathy in adults: A clinicopathological analysis. In Saudi Med J 2002; Vol. 23 (3): 282-286

Ageep AK . Assessment of adult peripheral lymphadenopathy in Red Sea State, Sudan. Int J Trop Dis Health 2012; 2, 24-32.

Albasri AM, El-Siddig AA, Hussainy AS, Alhujaily AS. Pattern of lymph node pathology in western Saudi Arabia. Asian Pac J Cancer Prev. 2014; 15:4677-4681
Al-Sohaibani MO, Satti MB, Ibrahim E, AlSowayan S. Histologic patterns of lymphadenopathy in the Eastern province of Saudi Arabia. Annals of Saudi Medicine 1990; 10: 516-520.

Al-Tawfiq JA, Raslan W. The analysis of pathological findings for cervical lymph node biopsies in eastern Saudi Arabia. J Infect Public Health 2012; 5, 140-4.

Habermann TM, Steensma DP. Lymphadenopathy. Mayo Clin Proc 2000; 75: 723

Kelly CS, Kelly RE. Lymphadenopathy in Children. Pediatr Clin North Am 1998; 45: 875-888.

Kochhar A, Duggal G, Singh K, Kochhar S. Spectrum of cytological findings in patients with lymphadenopathy in rural population of Southern Haryana, India - Experience in a tertiary care hospital. Int J Pathol 2012; 13, 2.

Lee JG, Helmus C. Cervical Lymph node biopsy. Mich Med 1970; 69: 581-583.

Memish ZA, Mah MW, Mahmood SA, Bannatyne RM, Khan M. Clinico-diagnostic experience with tuberculous lymphadenitis in Saudi Arabia. Clin Microbiol Infect 2000; 6: 137141.

Morad N, Malatani T, Khan AR, Hussain N. Peripheral Lymphadenopathy as a primary presenting sign. A study of 324 cases from Asir Region. Annals of Saudi Medicine 1990; 12: 72-75.

Naseem SS, Nagi AH, Ashraf M, et al. A pattern of lymphadenopathies seen in a tertiary care hospital in Lahore, Pakistan. Turk J Med Sci 2011; 41, 353-8.

O'Conor GT, Correa P, Christine B, Axtell L, Myers M. Hodgkin's disease in Connecticut. Histology and age distribution. J Natl Cancer Inst 1973; 36: 3-8.

Olu-Eddo AN, Ohanaka CE. Peripheral lymphadenopathy in Nigerian adults. J Pak Med Assoc 2006; 56, 405-8.

Powell DA. Tuberculous Lymphadenitis in Tuberculosis and Non-tuberculous Myobacterial Infections. In: Schlossberg D, editor. 4th ed. Philadelphia (PA): WB Saunders Company; 1999. p. 186-194. 
Roy A, Kar R, Basu D, Badhe BA. Spectrum of histopathologic diagnosis of lymph node biopsies: a descriptive study from a tertiary care center in South India over $5 \frac{1}{2}$ years. Indian J Pathol Microbiol 2013; 56, 103-8.

Siddiqui N, Ayub B, Badar F, Zaidi A. Hodgkin's lymphoma in Pakistan: a clinicoepidemiological study of 658 cases at a cancer center in Lahore. Asian Pac J Cancer Prev 2006; 7, 651-5.

Stalsberg H. Lymphoreticular tumors in Norway and in other European Countries. J Natl Cancer Inst 1973; 50: 1685-1702.

Talvalkar GV, Sampat MB, Gangadharan P. Hodgkin's Disease in Western India. Review of 1082 cases. Cancer 1982: 50: 353-359.

\begin{tabular}{|c|c|}
\hline \multicolumn{2}{|c|}{ Access this Article in Online } \\
\hline 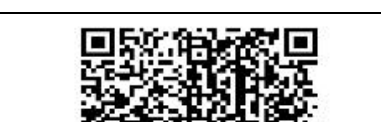 & $\begin{array}{l}\text { Website: } \\
\text { www.ijcrims.com }\end{array}$ \\
\hline 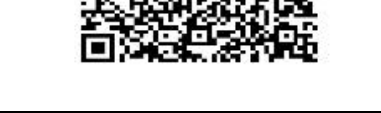 & \multirow[t]{2}{*}{$\begin{array}{l}\text { Subject: } \\
\text { Medicine }\end{array}$} \\
\hline Quick Response Code & \\
\hline
\end{tabular}

How to cite this article:

Salah A Abdelrahim, Ashraf A Deyab, Elsadig Y Mohamed, Abdul Lateef J. (2016). Pattern of adult lymphadenopathy among patients attending King Khalid hospital, Majmaah province, Kingdom of Saudi Arabia. Int. J. Curr. Res. Med. Sci. 2(11): 35-41.

DOI: http://dx.doi.org/10.22192/ijcrms.2016.02.11.004 